\title{
Aerogel, a high performance material for thermal insulation - A brief overview of the building applications
}

\author{
Larisa Meliță̌, Cristiana Croitoru \\ Technical University of Civil Engineering of Bucharest, code 020396. Lacul Tei Bvd. 122-124, Bucharest, Romania
}

\begin{abstract}
In this paper data regarding the utilization of aerogel as a promising material for thermal insulation of the residential and commercial buildings are presented. Also, research work and developments in synthesis, properties and characterization of silica aerogels will be addressed. Aerogel is a synthetic porous ultralight material derived from a gel in which the liquid component of the gel has been replaced with a gas. The result is a solid with extremely low density and low thermal conductivity. Sol-gel is the most used method of preparation. Aerogel melts at $1200^{\circ} \mathrm{C}$ and the thermal conductivity is almost 0 . Is a solid material with the smallest density because contains about $99.8 \%$ air. This material has almost unlimited potential, believing that they might find application in most human activities and areas. Aerogel insulation is a good choice because nearly neutralizes all three methods of heat transfer: convection, conduction and radiation. The resistance to convective transfer is given by the fact that air does not circulate in the material structure. The resistance to thermal transfer by conduction is given by the majority of gaseous components. If using a carbon based gel, a high resistance to radiation transfer is obtained. Therefore, the most used aerogel for thermal insulation is the silica aerogel with carbon as nanostructured material. The high price makes it currently inaccessible and less used material. But, inevitably, the aerogel will quickly become one of the most attractive materials in the future.
\end{abstract}

\section{Introduction}

Aerogel is a broad term used to talk about a group of materials that have been used since the 1960's in space travel, but are now finding uses across a whole range of industries [1]. Very recently A. Eychmüler [2] proposed a new definition: "an aerogel is a solid with meso- and macropores with diameters up to a few hundred nanometers and a porosity of more than $95 \%$ in which the dispersed phase is a gas". An aerogel (silica aerogel) is a special form of a highly porous material with a very low density $\left(0.003-0.15 \mathrm{~kg} / \mathrm{m}^{3}\right)$, high porosity, large specific surface areas $\left(500-1000 \mathrm{~m}^{2} / \mathrm{g}\right)$, low thermal conductivity and excellent transparency which can be prepared after replacing the liquid component of the wet gel with air [3]. It is composed of individual nanosized particles that are connected to form a tridimensional network [4].

Due to the special properties, the aerogels can be used in building applications as thermal and acoustic materials and, also in a wide range of other domains e.g. absorbents, shock absorbers, nuclear waste storage, batteries and catalysts etc. [5].

The Paris Agreement marked a turning point in the call to limit global warming. Seizing on that momentum, rapid deployment of energy-efficient and low-carbon solutions for buildings and construction can help put the world on a sustainable trajectory. Energy use in buildings has intensely increased over the past decade due to population growth, required indoor environmental quality, increased time spent inside and demand for building function etc. [6]. There is a growing interest to address energy use and emissions from buildings and constructions if ambitions for a $2^{\circ} \mathrm{C}$ decrease in annual temperature are envisaged. The construction of new buildings is increasing at a high rate. More challenging is that two-thirds of those new buildings are expected to occur in countries that do not currently have mandatory building energy codes in place [7]. Buildings are responsible for approximately $40 \%$ of energy consumption and $36 \%$ of $\mathrm{CO}_{2}$ emissions in the EU. Currently, about $35 \%$ of the EU's buildings are over 50 years old and nearly $75 \%$ of the building stock is energy inefficient, while only $0.4-1.2 \%$ (depending on the country) of the building stock is renovated each year [8]. More, $70 \%$ of this amount is solely consumed for heating and cooling applications for both residential and commercial buildings [4].

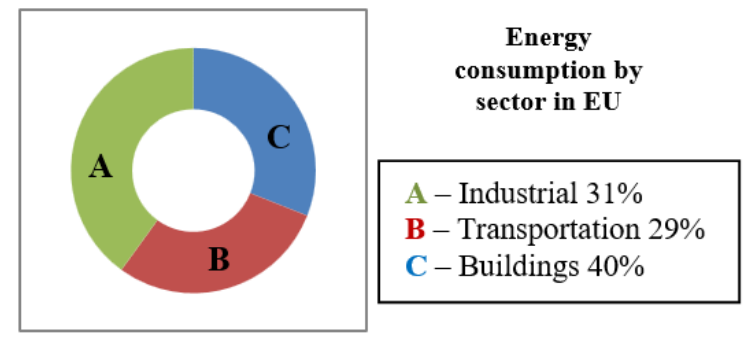

Fig. 1. Energy consumption categories.

\footnotetext{
$\overline{{ }^{*} \text { Corresponding author: larisamelita@gmail.com }}$
} 
In EU households, space heating is $32-33 \%$ of the total energy use in buildings (in residential and commercial buildings, respectively). Cooling is a fairly small share of total energy use, but demand from households and businesses such as the food industry is increasing during the warm season [9]. The context at European and International level is showing an amplified interest in new building materials which decrease the energy demand, especially related to heating sector.

\section{Classifications of aerogels}

There are five types of aerogels: silica, metal oxide, organic, carbon, and hybrid and composite aerogels [10]. Of these, the silica aerogel is the most extensively investigated and used type.

\subsection{Silica aerogels}

For the first time, silica aerogels were invented by S.S. Kistler in 1931; were made from inorganic precursors and consist of a cross-linked internal structure of $\mathrm{SiO}_{2}$ chains with a large number of air-filled pores [11]. The three-dimensional network of silica aerogels is obtained, as a result of the precursor's polymerization that contains silicon (-Si-) atoms which forms siloxane bridges ( $\equiv \mathrm{Si}-$ $\mathrm{O}-\mathrm{Si} \equiv)$.

The most important properties of silica aerogels are presented in Table 1 [12].

Table 1. Typical structural properties of silica aerogels.

\begin{tabular}{|c|c|}
\hline Property & Values \\
\hline Density $\left(\mathrm{kg} \cdot \mathrm{m}^{-3}\right)$ & $3-350$ \\
\hline Pore diameter (nm) & $1-100$ \\
\hline Porosity (\%) & $85-99.9$ \\
\hline $\begin{array}{l}\text { Thermal conductivity } \\
\left(\mathrm{W} \cdot \mathrm{m}^{-1} \cdot \mathrm{K}^{-1}\right)\end{array}$ & $0.01-0.02$ \\
\hline $\begin{array}{l}\text { Thermal tolerance } \\
\text { temperature }\left({ }^{\circ} \mathrm{C}\right)\end{array}$ & $\begin{array}{c}500 \\
\text { (Melting point 1200) } \\
\end{array}$ \\
\hline Surface area $\left(\mathrm{m}^{2} \cdot \mathrm{g}^{-1}\right)$ & $600-1000$ \\
\hline Refractive index & $1 .-1.05$ \\
\hline $\begin{array}{l}\text { Coefficient of linear } \\
\text { expansion }\left(1 /{ }^{\circ} \mathrm{C}\right)\end{array}$ & $2.0-4.0 \times 10^{-6}$ \\
\hline $\begin{array}{c}\text { Transmittance in } 0.5-2.5 \mu \mathrm{m}, \\
3.7-5.9 \mu \mathrm{m}\end{array}$ & $0.80-0.95$ \\
\hline Tensile strength $(\mathrm{kPa})$ & 16 \\
\hline $\begin{array}{l}\text { Longitudinal sound speed } \\
\qquad\left(\mathrm{m} \cdot \mathrm{s}^{-1}\right)\end{array}$ & $100-300$ \\
\hline
\end{tabular}

Silica aerogels have a variety of applications in the field of civil infrastructure, including heat insulation of buildings, particularly in areas short of space and in areas where optical transparency (e.g. windows) or translucency (e.g. skylights) are required: for example, monolithic aerogel between two $4 \mathrm{~mm}$ float glasses gave a $62 \%$ reduction in heat losses, with a $17 \%$ reduction in light transmittance when compared to a double glazing with a low-e layer [13]. Also, they are used as translucent heat insulators in solar collectors and high performance insulated building render [14].

The silica aerogel can be used as well in combination with other construction materials, increasing the insulating properties, e.g. foam concrete reinforced $\mathrm{SiO}_{2}$ aerogel (FC-SA) material. Thus, the thermal conductivity of FC-SA composite was measured as low as $0.049 \mathrm{~W} / \mathrm{m} \mathrm{K}$, which was a $48.4 \%$ decrease from foam concrete [15].

\subsection{Metal oxide aerogels}

If precursors as oxides of transition metals such as aluminium oxide $\left(\mathrm{Al}_{2} \mathrm{O}_{3}\right)$, vanadium oxide $\left(\mathrm{V}_{2} \mathrm{O}_{5}\right)$, chromium oxide $\left(\mathrm{Cr}_{2} \mathrm{O}_{3}\right)$, titanium oxide $\left(\mathrm{TiO}_{2}\right)$, iron oxide $\left(\mathrm{Fe}_{2} \mathrm{O}_{3}\right)$ or zirconium oxide $\left(\mathrm{ZrO}_{2}\right)$ are used for synthesizing gels, the resulting aerogels are named metal oxide aerogels and are other major class of inorganic aerogels. They have the pores sizes from 1 to $25 \mathrm{~nm}$, the specific surface area varies from 81 to $785 \mathrm{~m}^{2} \cdot \mathrm{g}^{-1}$, the extremely low density between $0.06 \mathrm{~g} \cdot \mathrm{cm}^{-3}$ for $\mathrm{Al}_{2} \mathrm{O}_{3} / \mathrm{SiO}_{2}$ precursor to $0.54 \mathrm{~g} \cdot \mathrm{cm}^{-3}$ for $\mathrm{Cr}_{2} \mathrm{O}_{3}$ precursor, and a very high porosity who varies between $77 \%$ to $96 \%$ [16].

These types of aerogels are mostly used for synthesis of the carbon nanotubes (CNT), as magnetic nanostructures, as high-temperature catalyst supports or as energetic materials [17].

\subsection{Organic and carbon aerogels}

$\mathrm{RF}$, resorcinol-formaldehyde aerogels were first time synthesized in 1992 by Pekala et al. as the reaction between resorcinol with fenolformaldehyde in aqueous medium, in the presence of a base catalyst, sodium bicarbonate [18]. Then the polycondensation reactions were obtained with different catalyst content, followed by the solvent exchange and by the supercritical drying. , As it can be observed from Table 2, RF aerogels may even have lower thermal conductivity from the organic aerogels, of $0.012 \mathrm{~W} \cdot \mathrm{m}^{-1} \cdot \mathrm{K}^{-1}$, besides the silica aerogels which have reported a lowest value of $0.017 \mathrm{~W} \cdot \mathrm{m}^{-1} \cdot \mathrm{K}^{-1}$.

Organic aerogels can be prepared from a great variety of monomeric or polymeric precursors such as: melamine-formaldehyde, phenol-furfural cresolformaldehyde, polymeric isocyanate, phenol melamine, polyvinyl chloride. The properties of these aerogels largely depend by the used precursors. Organic aerogels are ideal materials for thermal and acoustic insulators, membranes for gas separation, catalyst supports, dielectrics and precursors for the electrically conducting carbon aerogels production [10].

Carbon aerogels are derived from organic aerogels and are amorphous carbon materials with highly porosity which contain interconnected clusters of carbon nanoparticles with diameters between 3 and $20 \mathrm{~nm}$ respectively. To obtain carbon aerogels from organic aerogels, temperatures above $600{ }^{\circ} \mathrm{C}$ are necessary for a 
pyrolysis or carbonization process in an inert gas atmosphere (helium, nitrogen or argon). A porous carbon network, including both graphitic and amorphous regions with a large amount of disorder, is formed. Carbon aerogels are promising materials like: electrodes for hydrogen and electrical storage, thermal and acoustic insulators, adsorbents, sensors, and media for capacitive deionization and catalyst supports [19] [20].

\subsection{Hybrid and composite aerogels}

The most studied hybrid aerogels contain both inorganic and organic phases and nanoparticles into the gel matrix, which are blended with cross-linked polymers and reinforced with fibres and filler, forming interpenetrating networks [21] [22] [23]. These aerogels have been obtained to improve the mechanical properties, the physical properties and the aerogels processing also.

The composite aerogels as carbon fibre reinforced composite are obtained through copyrolysis of soft fibres as polyacrylonitrile (PAN) and RF aerogel matrix [24]. Through this obtaining process the toughness, strength, and thermal conductivity of the aerogels are improved.

Examples of this type of aerogels could be nanocomposite carbon aerogels containing carbon nanotubes (CNT), cross-linked polymer aerogels, functional nanocomposite aerogels which contain metal or metal oxide nanoparticles in the aerogel matrix with unique electrical, catalytic, optical, and magnetic properties. Other examples could be the silica aerogels containing transition metal oxide nanoparticles, such as $\mathrm{NiO}, \mathrm{ZnO}, \mathrm{TiO}_{2}, \mathrm{Al}_{2} \mathrm{O}_{3}, \mathrm{CuO}$ and $\mathrm{CoFe}_{2} \mathrm{O}_{4}$ or carbon aerogels containing nanoparticles of different metals, such as $\mathrm{Cr}, \mathrm{Zr}, \mathrm{Mo}, \mathrm{Fe}, \mathrm{W}, \mathrm{Co}, \mathrm{Ni}, \mathrm{Pd}, \mathrm{Pt}, \mathrm{Cu}$ and $\mathrm{Ag}$ [25] [26] [27] [28] [29].

\section{Thermal conductivity performance}

and

Due to high porosity and nanometres pores size, the aerogels have a very low thermal conductivity $(\approx 0.01$ $\left.\mathrm{W} \mathrm{m}^{-1} \cdot \mathrm{K}^{-1}\right)$, a low solid skeleton conductivity, a low gaseous thermal conductivity and a low radiative infrared transmission [30] [31], explained by three mechanisms: solid conductivity, gaseous conductivity, and infrared transmission. These thermal performances make the aerogel a special thermal insulations material than other.

In the aerogel skeleton the presence of a very small fraction of solid silica $(\approx 1-10 \%)$ [32], determines a lower solid conductivity therefore transmit a lower energy.

Overall, the low gaseous thermal conductivity, $\lambda_{g}$ of the aerogels can be explained by Knudsen effect which expresses the gaseous conduction in a porous media as function of the pore size characteristics and the air pressure and is depicted in eq. 1 and eq. 2 .

$\lambda_{g}=\frac{\lambda_{g, 0}}{1+2 \beta K_{n}}$

where:
$K_{n}=\frac{I_{\text {mean }}}{\delta}$ and $I_{\text {mean }}=\frac{k_{B} T}{\sqrt{2} \pi d_{g}^{2} P g}$

where $K_{n}$ is the Knudsen number (the ratio between the mean free path $I_{\text {mean }}$ of the air molecules and the characteristic sizes of pores diameter, $\delta), d_{g}$ is the diameter of the gas molecules, $k_{B}$ the Boltzmann constant, $T$ the temperature, $P_{g}$ the gas pressure and $\beta$ a constant between 1.5 and 2 depending on the gas type, the solid material and the temperature, and characterize the efficiency of the energy transfer when the gas molecules hit the solid structure of the material [5].

The silica aerogels are reasonably transparent in the infrared spectrum and an important parameter that influences the thermal transport is the optical thickness of the sample. The radiative transport becomes a dominant mode of thermal conduction at higher temperatures, i.e. above $200^{\circ} \mathrm{C}$, but at low temperatures the radiative transport is low also. In Figure 2 it can be observed the transmittance of a silica aerogel in the UV, VIS and NIR spectrum (top) and in the IR spectrum (bottom) with representative bands of alcohol at (3200$3600) \mathrm{cm}^{-1}$, of carbonyl at (1690-1760) $\mathrm{cm}^{-1}$ and of carboxyl at $1080-1300 \mathrm{~cm}^{-1}$ respectively.
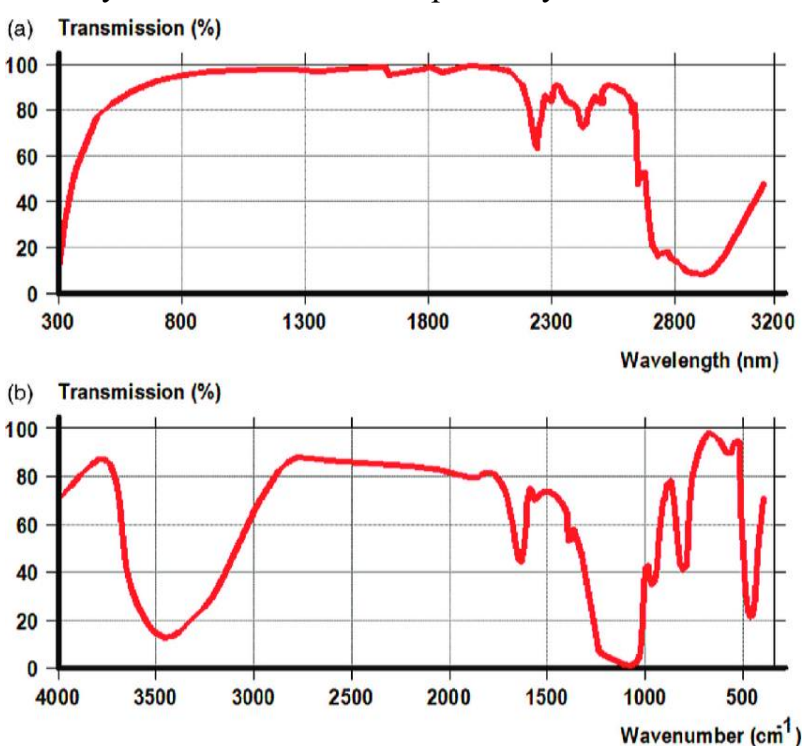

Fig. 2. The transmittance of a silica aerogel in the UV, VIS, NIR spectrum and in the IR spectrum, adapted from [33].

Moreover, the radiative transfer of the silica aerogels can be eliminated by adding carbon black in the fabrication process and thus the infrared radiation is either absorbed or scattered. At ambient pressure the thermal conductivity of silica aerogels, without radiative transfer, is of $13.5 \cdot 10^{-3} \mathrm{~W} \cdot \mathrm{m}^{-1} \cdot \mathrm{K}^{-1}$, and at a pressure of $50 \cdot 10^{-3}$ bar or less is of $410^{-3} \mathrm{~W} \cdot \mathrm{m}^{-1} \cdot \mathrm{K}^{-1}$. For buildings purposes, at ambient temperature, the aerogel insulations has a thermal conductivity between 13.1 and $13.6 \cdot 10^{-3}$ $\mathrm{W} \cdot \mathrm{m}^{-1} \cdot \mathrm{K}^{-1}$ range, and remain almost the same till a temperature of $200^{\circ} \mathrm{C}$ [34].

In Table 2 the values of minimum thermal conductivity of most used organic aerogels experimentally obtained are presented. The values depend on the chemical nature of the solid phase as well as on the amount of the solid in the matrix. 
Table 2. Thermal conductivities of the organic aerogels.

\begin{tabular}{|c|c|c|c|}
\hline Aerogels & $\begin{array}{c}\text { Thermal } \\
\text { conductivity, } \\
\mathbf{W} / \mathbf{m} \cdot \mathbf{K}\end{array}$ & $\begin{array}{c}\text { Pore size, } \\
\mathbf{n m}\end{array}$ & References \\
\hline Polyurea & 0.013 & $6.6-54$ & {$[35]$} \\
\hline $\begin{array}{c}\text { Resorcinol } \\
\text { formaldehide }\end{array}$ & 0.012 & $10-20$ & {$[36]$} \\
\hline $\begin{array}{c}\text { Polyciclopent } \\
\text { adiene }\end{array}$ & 0.017 & - & {$[37]$} \\
\hline $\begin{array}{c}\text { Polyurethane } \\
\text { Cellulose }\end{array}$ & 0.022 & $8.3-66.5$ & {$[38]$} \\
\hline
\end{tabular}

\section{Building applications of aerogels}

To reach the European Union 2020 targets energy and climate targets, improving energy efficiency of buildings is required as an important measure [40]. In this regard, the researchers from universities and industry investigate new intelligent materials with a strong impact on the field of the built environment, especially considering thermal insulation of the buildings.

Silica aerogels are a new and efficient alternative to traditional insulation. Because of their outstanding properties, especially of the low thermal conductivity, light-weight and sound-proof can be used as building components for a variety of purposes. However, the costs of these materials are still high for many industries, including for the building industry. The market share of aerogels tripled to $83 \mathrm{M}$ in 2008 , was valued at 221.8 M\$ in 2013 and it is estimated to reach $1,896.6 \mathrm{M} \$$ by 2020 [41]. Thus, the researches continue to develop new technology to improve the insulation performance and to reduce the production costs of aerogels.

For building applications, the granular aerogel-base translucent insulation materials and transparent monolithic aerogel are the most used [14]. Generally, if the monolithic aerogels possess superior thermal and optical properties, are expensive to be produced, needs long processing times and require to be protected from tension and moisture, the granular aerogels dominate the commercial market, even has low performance but are most robust, cheaper and easier to be produced at the commercial scale [38] [39]. These aerogels are most used for achieving the roofs, facades, walls or insulation bricks (aero-bricks) [40] and windows, but also for the sound insulation, fire retardation and air purification. In Figure 3 are depicted few examples of aerogel materials used in the buildings construction. For old buildings the aerogel can be used in the restoration and reconstruction of the historical buildings[42].

Aerogel can be also used as interior and exterior insulated plasters for breathable building envelopes and facades [43].
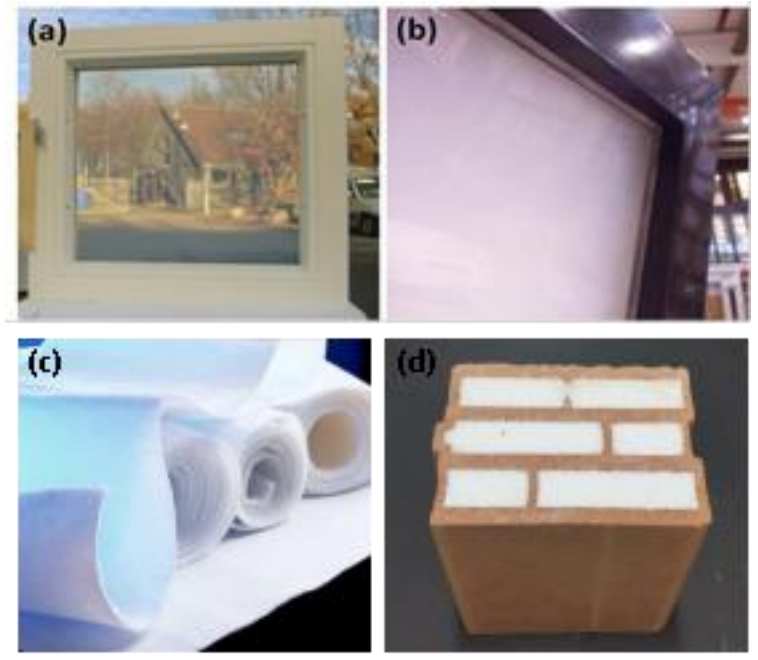

Fig. 3. (a) Specular aerogel glazing; (b) Diffuse aerogel glazing [42]; (c) Aerogel as thermal insulation material for building applications (Aspen Aerogel Inc.); (d) Brick with aerogel filling [40].

By far, Aspen Aerogels and Cabot Corporation from the U.S.A. are the major companies that have been involved in the large-scale industrial production of the silica-based flexible blankets and granular materials for the insulation market [10]. In Table 3 the commercial aerogel suppliers from Europe are presented.

Table 3. Commercial aerogel suppliers in Europe

\begin{tabular}{|c|c|c|c|c|}
\hline \multirow{9}{*}{ Europe } & Country & Producer & $\begin{array}{c}\text { Chemical } \\
\text { nature of the } \\
\text { aerogel }\end{array}$ & $\begin{array}{c}\text { Aerogel } \\
\text { form }\end{array}$ \\
\hline & Germany & BASF SE & Polyurethane & $\begin{array}{l}\text { Monolithic } \\
\text { panels }\end{array}$ \\
\hline & \multirow{2}{*}{ Sweden } & Airglass & $\begin{array}{l}\text { Transparent } \\
\text { silica }\end{array}$ & Monoliths \\
\hline & & $\begin{array}{l}\text { Svenska } \\
\text { Aerogel }\end{array}$ & Silica & $\begin{array}{l}\text { Powder, } \\
\text { granules }\end{array}$ \\
\hline & Portugal & $\begin{array}{l}\text { Active } \\
\text { Aerogels }\end{array}$ & $\begin{array}{l}\text { Silica } \\
\text { composites }\end{array}$ & Sheets \\
\hline & \multirow{3}{*}{ Spain } & $\begin{array}{l}\text { Green } \\
\text { Earth } \\
\text { Aerogels }\end{array}$ & $\begin{array}{l}\text { Silica from } \\
\text { rice, wastes } \\
\text { and husks }\end{array}$ & $\begin{array}{l}\text { Powder, } \\
\text { granules }\end{array}$ \\
\hline & & $\begin{array}{l}\text { Enersens } \\
\text { SAS }\end{array}$ & Silica & $\begin{array}{l}\text { Powder } \\
\text { /small } \\
\text { monoliths }\end{array}$ \\
\hline & & $\begin{array}{l}\text { Keey } \\
\text { Aerogels }\end{array}$ & $\begin{array}{l}\text { Mainly silica, } \\
\text { silica } \\
\text { incorporated in } \\
\text { support matrix }\end{array}$ & Particles \\
\hline & $\begin{array}{l}\text { Switzerla } \\
\text { nd }\end{array}$ & Nexaero & $\begin{array}{l}\text { Hydrophobic } \\
\text { silica }\end{array}$ & Particles \\
\hline
\end{tabular}

\subsection{Aerogel applications in roofs, facades and windows}

From literature, it can be observed that the aerogel applications in buildings for daylighting goals are more and more widespread. One example of high-performance translucent building system with aerogel is Kalwall Company who offers the most highly insulated light transmitting products. Thus, in Figure 4 is illustrated a building with pyramid skylights, designed for rapid installation from the outside and quick removable. 


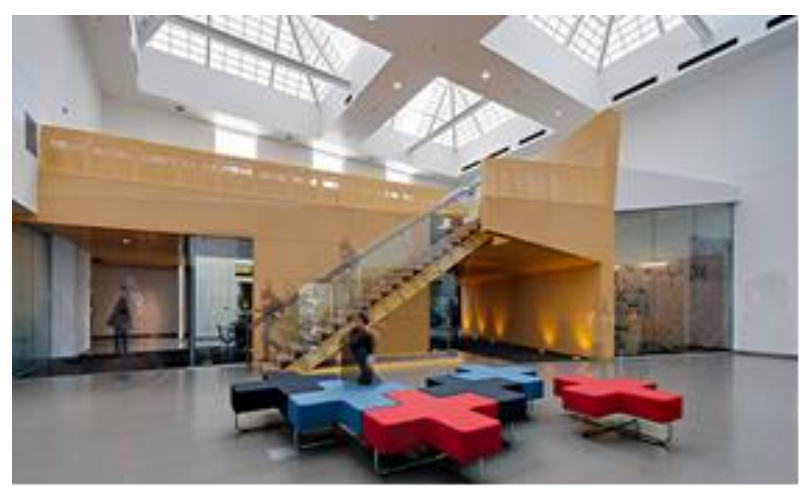

Fig. 4. Roof with skylights in Paradise Valley Community College / Phoenix, Arizona, USA from Kalwall Company.

In Figure 5 another application that can be mention is an aerogel insulation of an old brick building. The top floor is insulated with a thin layer of aerogel insulation while the ground floor is not. From the thermographic image with a thermal camera (Fig. 5 right) it can be observed that is a considerable amount of heat loss from the ground floor towards the top floor. This observation is correlated with the aerogel insulation which represents an efficient barrier to the heat loss.
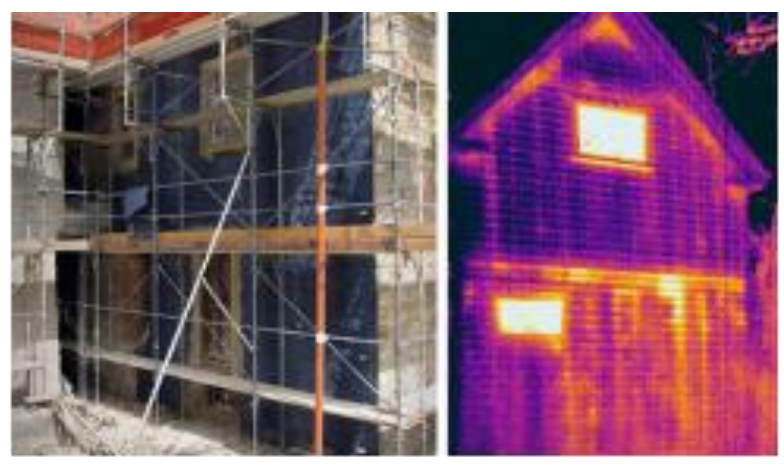

Fig. 5. (left) Retrofitting of an old brick dwelling with Aspen aerogel insulation; (right) Thermographic image of the building [41].

Schultz et al. [44] carried out an EU project on super insulating glazing based on monolithic silica aerogel. The prototypes measuring approximate $55 \times 55 \mathrm{~cm}^{2}$ and have been made with $15 \mathrm{~mm}$ evacuated aerogel between two layers of low-iron glass where a centre heat loss coefficient was found below $0.7 \mathrm{~W} / \mathrm{m}^{2} \cdot \mathrm{K}$ and the solar transmittance of $76 \%$ [11]. Other example of monolithic aerogel-based window in combination with the technology of vacuum glazing is presented by Jensen et al. [45]. The overall heat loss coefficient was $U_{\text {windows }}=$ $0.66 \mathrm{~W} / \mathrm{m}^{2} \cdot \mathrm{K}$ and the noise reduction of the glazing was measured to $33 \mathrm{~dB}$, for an evacuated glazing with 13.5 $\mathrm{mm}$ thick aerogel. With these results, in the climate conditions of Denmark for a new built single family house where the triple-layered argon-filled glazing is replaced with aerogel glazing, the saved energy is of $1180 \mathrm{kWh} /$ year (19\%) [46].

ZAE Bayern (Germany) develops granular silica aerogels integrated into highly-insulating translucent glazing. The obtained heat transfer coefficients were less than $0.4 \mathrm{~W} / \mathrm{m}^{2} \cdot \mathrm{K}$ and the optimized granular layers provided high solar transmittance of $65 \%$ for thickness of $20 \mathrm{~mm}$ [47] [48] [49].

Gao et al. [50] explain that the recent buildings practices have shown that aerogel glazing can be used as a multifunctional building envelope component for different purposes. An example is the Levanger primary school, Norway, (Fig. 6) where the entire second floor has built with two glazing systems: an aerogel glazing for the upper windows and a normal clear glass glazing for the low windows to optimize the visual comfort as access of diffuse light and outside view.
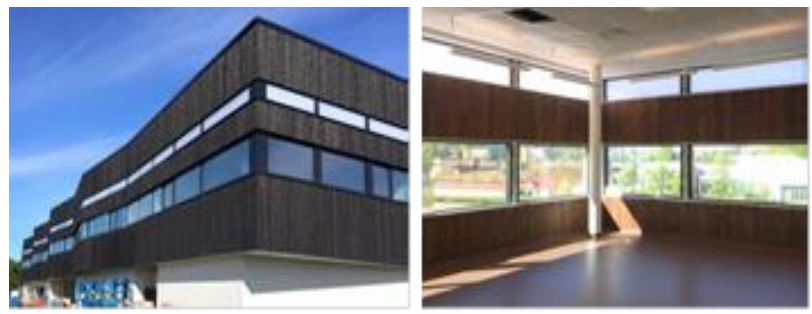

Fig. 6. Levanger primary school, Norway [50].

Wang et al. [51] accomplish a feasibility analysis of five types of aerogel glazing's in five climate zones of China: Beijing, Shanghai, Harbin, Guangzhou and Kunming. The constructions with $4 \mathrm{~mm}$ clear glass outer $+15 \mathrm{~mm}$ aerogel interlayer $+4 \mathrm{~mm}$ clear glass inner has the heat transfer coefficient of $0.72 \mathrm{~W} / \mathrm{m}^{2} \mathrm{~K}$ and the shading coefficient of 0.59 respectively, the best thermal characteristics obtained among the evaluated constructions.

In a case study from 2015, a silica-aerogel filled super-insulating glazing system in a commercial building in Hong Kong was proposed, proving that the energy consumption of HVAC system was reduced by 4-7\% [52]. A numerical and experimental study showed that the Aerogel insulating panel (AIP) has decreases of $\sim 20 \%$ and $\sim 40 \%$ in the fluctuation amplitude of the internal temperature and heat flux, respectively, compared with the traditional insulating walls [53]. Moreover, this kind of insulation material can be further used in renovation works. Berardi [43] showed that high thermal resistance values could be obtained installing thin aerogel-enhanced materials in the opaque and transparent envelope, with overall building energy savings up to $34 \%$, with low impact on the building functionality and use.

\subsection{Aerogel applications for sound insulation, fire delay and air purification}

In case of the insulation plates with aerogel, their performances depend on binder and can be positively influenced by choosing the right binding material where a notably improved sound was observed. As example, Gibiat et al. [54] investigated the acoustic properties of the cylindrical silica aerogels. They measured the sound velocity, for low ultrasonic frequencies, and the acoustical impedance in audible range. It was observed that, the low-density aerogels could exhibit unexpected attenuation for well-defined frequency bands and the 
results greatly depend on the geometry/boundary conditions imposed to the samples.

Buratti and Moretti [13] investigated the light transmittance, $\tau$ and the weight sound insulation index, $\mathrm{R}$ in eight samples of glass assembled with monolithic and granular aerogel in the interspace. They found that the light transmittance in the monolithic aerogel was better ( $\tau=0.60)$ than the granular one $(\tau=0.27)$ and the weight sound insulation index $\mathrm{R}$, for the aerogel window sample was $3 \mathrm{~dB}$, higher than the same window with air in interspace.

Also the aerogels are capable to the efficient removal of many pollutants from indoor environment such as: chloride from tap water, hydrocarbons $\left(\mathrm{CH}_{3} \mathrm{CHO}\right.$ and $\mathrm{CH}_{3} \mathrm{CHO}$ ) from cigarettes, $\mathrm{NO}_{\mathrm{x}}$ and $\mathrm{SO}_{\mathrm{x}}$ from incomplete burning of gas, VOC from organic solvents, formalin from paints and furniture who are responsible for health problems [55]. Aerogel-prepared nanocrystals of $\mathrm{MgO}, \mathrm{CaO}$, and $\mathrm{Al}_{2} \mathrm{O}_{3}$ with specific surface area of up to $500 \mathrm{~m}^{2} \mathrm{~g}^{-1}$, have shown remarkably high capacity to destructively adsorb VOCs under the atmospheric pressure and temperature [56].

A promising way to battle with climate and environmental changes, especially with rising atmospheric temperature, is the minimization of $\mathrm{CO}_{2}$ emissions into the atmosphere from all fields of activity. In this regard, recent investigations have focused in using aerogels as new $\mathrm{CO}_{2}$ capture materials by controlling their chemo-physical properties. An interesting and efficient example is given by Minju et al. [57] who studied the effect of 2 amines (3aminopropyltrimethoxysilane, APTMS and polyethyleneimine, PEI) loaded to silica aerogels particles used in $\mathrm{CO}_{2}$ gas adsorption. The investigations concluded that the aerogels loaded with amines are good sorbents, with high sorption capacity toward target component, from 0.65 to $1.1 \mathrm{mmol} \mathrm{g}^{-1}$ of $\mathrm{CO}_{2}$ adsorption, correlated with the amine functionality/contents and pore structure, pore volume (from 0.1 to $0.5 \mathrm{~cm}^{3} \mathrm{~g}^{-1}$ ) of the adsorbent, who are essential for achieving the better results in terms of process selectivity and sorption capacity.

Because the aerogels are non-flammable materials, due to their chemical structure and their melting point, who is very high $\left(1200^{\circ} \mathrm{C}\right)$, they can be used inside buildings to avoid spreading fire from one place to another.

\subsection{Advantages of using aerogel in old buildings restoration and building retrofits}

Aspen Aerogels Company, U.S.A. has developed a high performance thermal insulation material called SPACELOFT for residential and commercial buildings envelopes [58]. This material is very versatile, the useful floor area is saved and the efficiency energy is improved. It is used on the internal and external walls, on the floors, terrace and balcony, windows, doors and fenestration inserts, in zero emissions buildings, passive houses, government retrofit programs and tiny house projects. Overall, the heat transfer of SPACELOFT is very low, ranging from 1 to $0.2 \mathrm{~W} / \mathrm{m}^{2} \mathrm{~K}$.

Berardi [43] investigated the aerogel glazing systems, the aerogel plasters, the aerogel concrete tiles and panels and the aerogel fibre blankets in a retrofit of an educational building: the Civil Engineering Department of Ryerson University, Toronto, Canada who was constructed in 1931. Based on a reliable virtual model, several actions such as: annual saving, the total intervention cost, and the payback period were investigated and had shown that the energy saving can be achieved, from 17 years to several decades, depending on which part of the building is insulated with aerogel materials. It is important to mention that, it may expect that the energy saving, in a building located in more mild climates area than Toronto, to be higher.

Aerogel can be used with success as superior thermal insulation, for facades with slim and light construction, because of his excellent dimensional stability. Also, the aerogel can be used for restoration and preservation of historical features of buildings, as insulation material with fire retardation property, with low thermal conductivity and low density without the need for major changes to the building structures such us windows, doors, roofs and facades.

\subsection{Predictions and future research}

For the future researches and developments of thermal insulation technologies with aerogel an important target should be focused on the manufacturing costs reduction; thus, increase the competitiveness of aerogel products with conventional materials. E.g. the cost of an aerogel window is six times higher than the conventional doubleglazed window and the cost is nearly $20 £ / \mathrm{m}^{2}$ [12]. However, the price of aerogel could drop below US $\$ 1500 / \mathrm{m}^{3}$ by 2020 [59]. Despite the high costs, the aerogel can be seen as a future insulation material for some other domains, like textile industry [60] or cryogenic and high-temperature thermal insulation for space launch applications [61].

Other targets could be the improving of the appropriate balance between thermal and mechanical properties and to not change or decrease the valuable features of the aerogel materials. High performances of the aerogels may be found in translucency and, why not, in transparency to obtain windows and skylights with high energy efficiency, to design and built energy efficient constructions. Also, the high flexibility, the versatility and the ease of use of aerogels, as insulation material requirements, can be improved by researchers and companies. In this regard, it is fundamental to ensure long term performance of aerogel-enhanced building products.

\section{Conclusion}

In this paper a brief overview of the aerogel insulation materials used in the buildings domain, considering both technical and economical performances of these materials is presented. The most important features that 
characterize the studied aerogel insulation materials are presented. Their remarkable and adjustable properties such as high porosity, very low density, extremely high specific surface area and low thermal conductivities make these materials attractive for researchers and engineers with the goal of developing new aerogel-based materials for energy-related applications. Also, reducing their production costs, through the development and discovery of new obtaining technologies represent a target for the academics and scientists.

Some relevant examples of building applications of the aerogel in roofs, facades and windows, for sound insulation, fire retardation and air purification and also, the advantages of using aerogels in the old buildings restoration and building retrofits were analyzed. It is expected, in the near future, the interest in the aerogel insulation to increase because of both thermal and acoustic properties. Besides the numerous positive aspects, two major disadvantages of using aerogel can be mentioned: the first one is the high cost compared to other conventional insulation materials, and the second ones is the dust occurred in the fabrication process which is very difficult to be eliminated. The manufacturers, in collaboration with researchers, try to develop new production technologies to minimize the resulted dust.

Nevertheless, because of the exceptional features and unlimited potential of the aerogel-based materials, practically, its applications could be encountered in all areas of activity.

\section{Acknowledgements}

This work was supported by a grant of the Romanian National Authority for Scientific Research, CNCS UEFISCDI, project number PN-III-P1-1.2-PCCDI-20170391.

\section{References}

1. Thomas, G.P., What is Aerogel? Theory, Properties and Applications, in AZO MATERIALS. 2012.

2. Ziegler, C., et al., Modern Inorganic Aerogels. Angewandte Chemie International Edition, 2017. 56(43): p. 13200-13221.

3. Soleimani Dorcheh, A. and M.H. Abbasi, Silica aerogel; synthesis, properties and characterization. Journal of Materials Processing Technology, 2008. 199(1): p. 10-26.

4. Ülker, Z., D. Sanli, and C. Erkey, Chapter 8 Applications of Aerogels and Their Composites in EnergyRelated Technologies, in Supercritical Fluid Technology for Energy and Environmental Applications, V. Anikeev and M. Fan, Editors. 2014, Elsevier: Boston. p. 157-180.

5. Baetens, R., B.P. Jelle, and A. Gustavsen, Aerogel insulation for building applications: a state-of-the-art review. Energy and Buildings, 2011. 43(4): p. 761-769.
6. Cao, X., X. Dai, and J. Liu, Building energyconsumption status worldwide and the state-ofthe-art technologies for zero-energy buildings during the past decade. Energy and Buildings, 2016. 128: p. 198-213.

7. Agency, I.E., Global Status Report 2017. 2017.

8. Comission, E. Energy performance of buildings. 2019; Available from: https://ec.europa.eu/energy/en/topics/energyefficiency/energy-performance-of-buildings.

9. Ürge-Vorsatz, D., et al., Heating and cooling energy trends and drivers in buildings. Renewable and Sustainable Energy Reviews, 2015. 41: p. 85-98.

10. Karaaslan, M., J. F. Kadla, and F. Ko, LigninBased Aerogels. 2016. p. 67-93.

11. Cuce, E., et al., Toward aerogel based thermal superinsulation in buildings: A comprehensive review. Renewable and Sustainable Energy Reviews, 2014. 34: p. 273-299.

12. Riffat, S.B. and G. Qiu, A review of state-ofthe-art aerogel applications in buildings. International Journal of Low-Carbon Technologies, 2012. 8(1): p. 1-6.

13. Buratti, C. and E. Moretti, Glazing systems with silica aerogel for energy savings in buildings. Applied Energy, 2012. 98: p. 396-403.

14. Hanus, M.J. and A.T. Harris, Nanotechnology innovations for the construction industry. Progress in Materials Science, 2013. 58(7): p. 1056-1102.

15. Liu, S., et al., A novel building material with low thermal conductivity: Rapid synthesis of foam concrete reinforced silica aerogel and energy performance simulation. Energy and Buildings, 2018. 177: p. 385-393.

16. Hüsing, N. and U. Schubert, Aerogels-Airy Materials: Chemistry, Structure, and Properties. Angewandte Chemie International Edition, 1998. 37(1-2): p. 22-45.

17. Aegerter, M.A., N. Leventis, and M.M. Koebel, Aerogel Handbook ed. A.i. Sol-Gel and D.M.a. Technologies. 2011, New York: Springer New York.

18. Pekala, R.W., Organic aerogels from the polycondensation of resorcinol with formaldehyde. Journal of Materials Science, 1989. 24(9): p. 3221-3227.

19. Biener, J., et al., Advanced carbon aerogels for energy applications. Energy \& Environmental Science, 2011. 4(3): p. 656-667.

20. Glora, M., et al., Integration of carbon aerogels in PEM fuel cells. Journal of Non-Crystalline Solids, 2001. 285(1): p. 283-287.

21. Li, L., et al., Flexible Nanofiber-Reinforced Aerogel (Xerogel) Synthesis, Manufacture, and Characterization. ACS Applied Materials \& Interfaces, 2009. 1(11): p. 2491-2501.

22. Liao, Y., et al., Engineering thermal and mechanical properties of flexible fiberreinforced aerogel composites. Journal of Sol- 
Gel Science and Technology, 2012. 63(3): p. 445-456.

23. de la Rosa-Fox, N., et al., Nanoindentation on hybrid organic/inorganic silica aerogels. Journal of the European Ceramic Society, 2007. 27(11): p. 3311-3316.

24. Feng, J., C. Zhang, and J. Feng, Carbon fiber reinforced carbon aerogel composites for thermal insulation prepared by soft reinforcement. Materials Letters, 2012. 67(1): p. 266-268.

25. Worsley, M.A., et al., Mechanically robust and electrically conductive carbon nanotube foams. Applied Physics Letters, 2009. 94(7): p. 073115.

26. Leventis, N., et al., Nanoengineering Strong Silica Aerogels. Nano Letters, 2002. 2(9): p. 957-960.

27. Casula, M.F., A. Corrias, and G. Paschina, Iron oxide-silica aerogel and xerogel nanocomposite materials. Journal of NonCrystalline Solids, 2001. 293-295: p. 25-31.

28. The Sol-Gel Handbook. 2015: 2015 WileyVCH Verlag GmbH \& Co. KGaA.

29. Moreno-Castilla, C. and F.J. Maldonado-Hódar, Carbon aerogels for catalysis applications: An overview. Carbon, 2005. 43(3): p. 455-465.

30. Kistler, S.S. and A.G. Caldwell, Thermal Conductivity of Silica Aërogel. Industrial \& Engineering Chemistry, 1934. 26(6): p. 658662.

31. Hrubesh, L.W. and R.W. Pekala, Thermal properties of organic and inorganic aerogels. Journal of Materials Research, 2011. 9(3): p. 731-738.

32. Lee, J.K., G.L. Gould, and W. Rhine, Polyurea based aerogel for a high performance thermal insulation material. Journal of Sol-Gel Science and Technology, 2009. 49(2): p. 209-220.

33. LU, X., et al., Thermal Conductivity of Monolithic Organic Aerogels. Science, 1992. 255(5047): p. 971-972.

34. Lee, J.K. and G.L. Gould, Polydicyclopentadiene based aerogel: a new insulation material. Journal of Sol-Gel Science and Technology, 2007. 44(1): p. 29-40.

35. Rigacci, A., et al., Preparation of polyurethanebased aerogels and xerogels for thermal superinsulation. Journal of Non-Crystalline Solids, 2004. 350: p. 372-378.

36. Fischer, F., et al., Cellulose-based aerogels. Polymer, 2006. 47(22): p. 7636-7645.

37. 2020, E.C.D. 2020 climate \& energy package. Available from: https://ec.europa.eu/clima/policies/strategies/20 20 en.

38. Dowson, M., et al., Predicted and in situ performance of a solar air collector incorporating a translucent granular aerogel cover. Energy and Buildings, 2012. 49: p. 173187.
39. Akimov, Y.K., Fields of Application of Aerogels (Review). Instruments and Experimental Techniques, 2003. 46(3): p. 287299.

40. Wernery, J., et al., Aerobrick - An aerogelfilled insulating brick. Energy Procedia, 2017. 134: p. 490-498.

41. Jelle, B.P., Aerogel Insulation for Building Applications, in The Sol-Gel Handbook.

42. Lucchi, E., et al., Thermal performance evaluation and comfort assessment of advanced aerogel as blown-in insulation for historic buildings. Building and Environment, 2017. 122: p. 258-268.

43. Berardi, U., Aerogel-enhanced systems for building energy retrofits: Insights from a case study. Energy and Buildings, 2018. 159: p. 370381.

44. Schultz, J.M., K.I. Jensen, and F.H. Kristiansen, Super insulating aerogel glazing. Solar Energy Materials and Solar Cells, 2005. 89(2): p. 275285.

45. Jensen, K.I., J.M. Schultz, and F.H. Kristiansen, Development of windows based on highly insulating aerogel glazings. Journal of NonCrystalline Solids, 2004. 350: p. 351-357.

46. Schultz, J.M. and K.I. Jensen, Evacuated aerogel glazings. Vacuum, 2008. 82(7): p. 723729.

47. Reim, M., et al., Highly insulating aerogel glazing for solar energy usage. Solar Energy, 2002. 72(1): p. 21-29.

48. Reim, M., et al., Silica-aerogel granulate Structural, optical and thermal properties. Journal of Non-Crystalline Solids, 2004. 350: p. 358-363.

49. Reim, M., et al., Silica aerogel granulate material for thermal insulation and daylighting. Solar Energy, 2005. 79(2): p. 131-139.

50. Gao, T., B.P. Jelle, and A. Gustavsen, Building Integration of Aerogel Glazings. Procedia Engineering, 2016. 145: p. 723-728.

51. Wang, H., et al., Feasibility and optimization of aerogel glazing system for building energy efficiency in different climates. International Journal of Low-Carbon Technologies, 2014. 10(4): p. 412-419.

52. Huang, Y. and J.-1. Niu, Energy and visual performance of the silica aerogel glazing system in commercial buildings of Hong Kong. Construction and Building Materials, 2015. 94: p. 57-72.

53. Yang, J., et al., Numerical and experimental study on the thermal performance of aerogel insulating panels for building energy efficiency. Renewable Energy, 2019. 138: p. 445-457.

54. Gibiat, V., et al., Acoustic properties and potential applications of silica aerogels. Journal of Non-Crystalline Solids, 1995. 186: p. 244255 .

55. Zhang, Y., R. Yang, and R. Zhao, A model for analyzing the performance of photocatalytic air 
cleaner in removing volatile organic compounds. Atmospheric Environment, 2003. 37(24): p. 3395-3399.

56. Maleki, H., Recent advances in aerogels for environmental remediation applications: $A$ review. Chemical Engineering Journal, 2016. 300: p. 98-118.

57. Minju, N., et al., Amine impregnated porous silica gel sorbents synthesized from water-glass precursors for CO2 capturing. Chemical Engineering Journal, 2015. 269: p. 335-342.

58. Company, A.A. Aspen Aerogels Company. 2019; Available from: https://www.aerogel.com/.

59. Berardi, U., 17 - Aerogel-enhanced insulation for building applications, in Nanotechnology in Eco-efficient Construction (Second Edition), F. Pacheco-Torgal, et al., Editors. 2019, Woodhead Publishing. p. 395-416.

60. Du, Y. and H.-e. Kim, A Market Research on the Development Trends of Aerogel Daily Clothing. 한국의류산업학회지, 2019. 21(1): p. 96-103.

61. Fesmire, J.E., Aerogel insulation systems for space launch applications. Cryogenics, 2006. 46(2): p. 111-117. 